\title{
The effect of brain-derived neurotrophic factor single nucleotide polymorphism on memory of university students
}

\author{
Abolfazl Shayan Nooshabadi ${ }^{*}$ (ID), Mohammad Ali Dowlati ${ }^{2}$, Abdossaleh Zar \\ 1. Assistant of Motor Behavior, Department of Sport Sciences, Faculty of Literature and Humanities, Jahrom University, Jahrom, Iran \\ 2. Assistant Professor of Medical Genetics, Research Center for Biochemistry and Nutrition in Metabolic Diseases, Kashan University of \\ Medical Sciences and Health Services, Kashan, Iran \\ 3. Associate Professor of Exercise Physiology, Department of Sport Science, Faculty of Literature and Humanities, Persian Gulf University, \\ Boushehr, Iran
}

Recieved: 20 May. 2019

Revised: 23 Aug. 2019

Accepted: 14 Oct 2019

Keywords

Single nucleotide polymorphism Brain-derived neurotrophic factor Met-carriers

Memory

\section{Corresponding author}

Abolfazl Shayan Nooshabadi, Assistant of Motor Behavior, Department of Sport Sciences, Faculty of Literature and Humanities, Jahrom University, Jahrom, Iran

Email: Ab.shayana@gmail.com

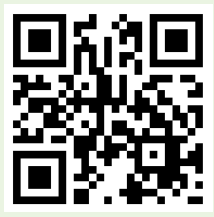

doi.org/10.30699/icss.22.1.61

\section{Abstract}

Introduction: Brain-derived neurotrophic factor (BDNF) is one of the most abundant neurotrophic factors in the adult brain associated with synaptic plasticity, learning, memory and cognitive processes reinforcement. The advent of val66met polymorphism in codon 66 of the BDNF gene, disrupted this protein's secretion. The purpose of the study is to investigate of the effect of brain-derived neurotrophic factor single nucleotide polymorphism on memory score and memory quotient.

Methods: One hundred native male students from Kashan University, Iran (mean age $21.60 \pm 2.20$ ) were randomly selected. After extraction of Genomic DNA, the polymerase chain reaction (PCR) was implemented by forwarding primer 5-ACTCTGGAGAGCGTGAAT-3 and reverse primer 5-ATACTGTCACACACGCTG-3, analyzing PCR by 1.5 percent Electrophoresis Gel. In the end, sequencing by ABI PRISM 7000 Sequencing Analyzer, some participants were identified without val66met polymorphism while the others were affected by the polymorphism (met-carrier). We used Wechsler memory tested assess memory score and memory quotient of participants. Also, we used from SPSS software for data analysis and test the research hypothesis.

Results: Results revealed that people without the polymorphism were significantly better than met-carriers in memory score and memory quotient $(\mathrm{P}<0.001)$. The study of Wechsler's subscales showed that this superiority was more affected by logical memory subscales and associative learning.

Conclusion: In general, the results represent the effect of val66met polymorphism on memory and memory quotient, so that the existence of this polymorphism in some people may weaken their ability in compression with people without polymorphism, due to disruption of BDNF secretion. 


\title{
اثر خندريختى تك نو كلئوتيدى عامل رشد عصبى مشتق شده از مغز بر حافظه دانشجويان
}

\author{
ابوالفضل شايان نوش آبادى" (DD، محمدعلى دولتى '، عبدالصالح زرّ

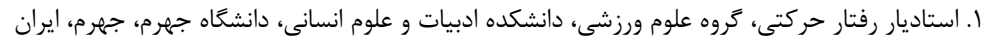

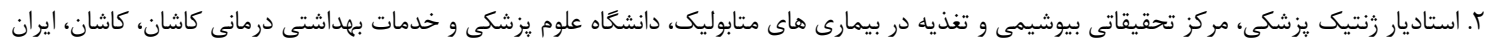

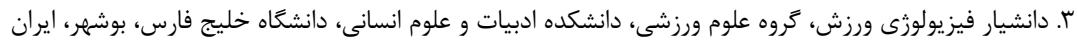

\section{ars}

مقدمه: عامل رشد عصبى مشتق شده از مغز (BDNF) يكى از فراوانترين عوامل نروتروفيك در مغز فرد بالغ است و با رشد، شكليذيرى سينايسى، يادگيرى، حافظه و تسهيل فرآيندهاى شناخنى در ارتباط است. وجود جندريختى Val66met در كدين 94 زن BDNF، ترشح اين بروتئين را دجار اختلال مى كند. لذا هدف از تحقيق حاضر بررسى اثر جندريختى تكى نوكلئوتيدى عامل رشد عصبى مشتق شده از مغز بر نمره و بهره حافظه بود.

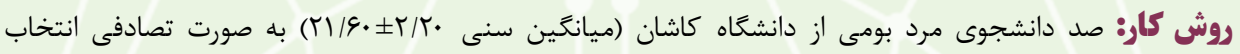
شدند. يُ از استخراج DNA زنوميك، انجام واكنش زنجيره يلى مراز (PCR) با استفاده از برايمر رو به جلو 5-ACTCTGGAGAGCGTGAAT-3 و برايمر معكوس 5-ATACTGTCACACACGCTG-3، تاييد صحت Sequencing با استفاده از زل الكتروفرز ه/ إدرصد و در نهايت تعيين توالى با استفاده از آناليزگر

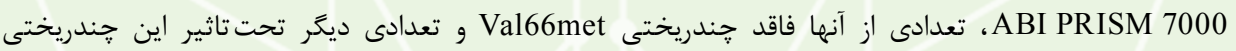
(حامل متيونين) شناسايى شدند. سيس با استفاده از آزمون حافظه وكسلر، نمره و بهره حافظه شركت كنندكان مورد آزمون قرار كرفت. در نهايت دادهها با استفاده از نرمافزار SPSS تحليل شد. يافته ها: نتايج نشان داد افراد فاقد جندريختى در نمره و بهره حافظه به صورت معنادارى بهتر از حاملان متيونين بودند (P<•|•l)

$$
\text { و يادگيرى تداعى بود. }
$$
نتيجه گيرى: به طور كلى نتايج نشان از تأثير جندريختى Val66met بر بهره حافظه دارد، به گونهاى كه وجود اين جندريختى در برخى از افراد احتمالاً از طريق اختلال در ترشح BDNF توانايى آنها نسبت افراد فاقد اين جندريختى را تضعيف مى كند.

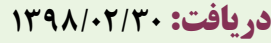

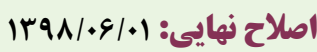

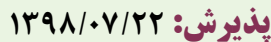

وازه内اى كليدى

جندريختى تك نوكلئوتيدى عامل رشد عصبى مشتق شده از مغز حاملان متيونين حافظه

نويسنله مسئول ابوالفضل شايان نوش آبادى، استاديار رفتار حركتى، گروه علوم ورزشى، دانشكده ادبيات و علوم انسانى، دانشكاه جهرم، رونى

جهرم، ايران

ايميل:Ab.shayana@gmail.com

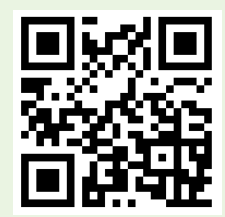

dol doi.org/10.30699/icss.22.1.61

مقلدمه

شناختى در ارتباط است (1). تحقيقات مختلف از طريق تنظيم بيان BDNF به شيوههاى مختلف، سعى در نشان دادن نقش آن در كارايى عملكردهاى شناختى داشتهاند. در اين تحقيقات ارتباط يادگيرى ترس با افزايش BDNF و گيرنده تيروسين كينازى آن در آميحدال موش (ז)، افزايش بيان تدريجى BDNF در قشر حركتى در اثر يادگيرى يك
عامل رشد عصبى مشتق شده از مغز Neurotrophic Factor (BDNF)) Brain-Derived و محافظت از سلولهاى عصبى، موجبات ابقاء آنها را فراهم مى كند. يكى از فراوانترين عوامل نروتروفيك در مغز فرد بالغ است و با مD رشد، شكل يذيرى سينايسى (Plasticity)، ياد گيرى و تسهيل فرآيندهاى 
جندريختى با شكل يذيرى كوتاه مدت قشر حركتى در ارتباط است (T ا -

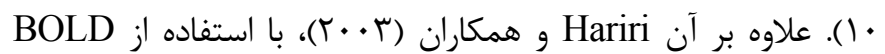
نشان دادند كه حاملان متيونين، در طول فرايندهاى رمزگذارى و FMRI بازيابى، فعالسازى هييو كاميى ضعيفترى نسبت به حاملان والين دارند. در اين تحقيق همجنين، حاملان متيونين در تكليف حافظه اخبارى

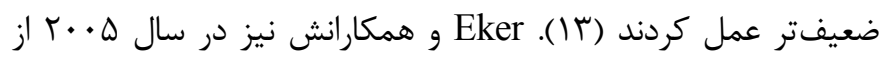
طريق بررسى ماده خاكسترى نواحى مختلف مغز به اين نتيجه رسيدند كه جندريختى BDNF اثر منفى معنادارى روى ساختارهايى از مغز كه در

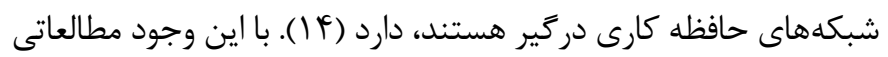
نيز وجود داشته است كه با يروتكل هاى نسبتا متفاوت نتوانستهاند اين يافته را تكرار كنند (ه) (1). همجنين با توجه به اثرات متفاوت روى رفتار حركتى و به ويره يادگيرى حركتى، برخى مطالعات قادر به نشان دادن

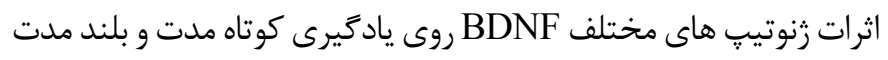
بودهاند، در حالى كه مطالعات ديخر در نشان دادن جنين تاثيراتى ناكام ماندهاند (9). در تحقيقى ديگر كه Tonacci و همكاران (Tו • ( انجام دادند، نشان داده شد كه حاملان متيونين نسبت به حاملان والين در در درانر كاركردهاى مربوط به حس بويايى دجار اختلالاتى بودند. نقص در اين كاركردها عامل مهرى در مبتلا شدن به بيمارىهاى تحليل برنده عصبى

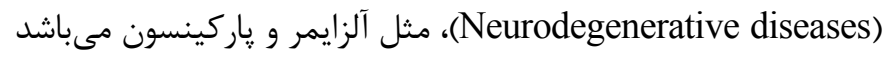
(IV) همجنين در بيماران با اختلال دو قطبى، حاملان متيونين تكليف مرتب كردن كارت ويسكانسين را، كه تكليفى است مربوط به عملكردهاى اجرايى لوب ييشانى، به شكل ضعيفترى انجام مى دهند (1 (1). با اين حال Freundlieb حاملان متيونين و حاملان والين در الكوهاى يادگيرى ينههان كوتاه مدت

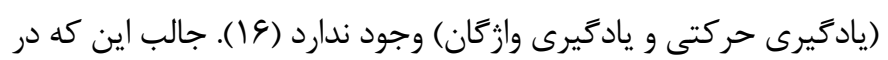
آزمايش Beste و همكاران ( • • • نشان داده شد حاملان متيونين نسبت به حاملان والين توانايى بازدارى پاسخ (Response inhibition) بهترى دارند (9 (1). از طرفى برخى تحقيقات تفاوتهاى آشكارى را در ميزان شيوع انواع زنوتي״ BDNF و همجنين ميزان تاثير گذارى رفتارى آنها در نزادهاى مختلف نشان داده اند (Y (Y- (Y). در ميان عملكردهاى شناختى حافظه قابليتى بنيادى است كه ييشنياز بسيار مهم براى انجام مطالبات روزانه است. اختلال در حافظه موجب كاهش سطح عملكرد شناختى و افت كارايى عملكردى فرد و افزايش اشتباهات مىشود و بدين ترتيب اختلال در عملكردهاى شناختى و يا كاهش سطح عملكرد مطلوب شناختى، همه جنبdهاى زندگى شامل: عملكرد تحصيلى، آموزشى، عملكرد شغلى، روابط اجتماعى و تقريبا همه فعاليتهاى روزمره را تحت تاثير قرار مىدهد (س)). همجنين شاخص
تكليف دسترسى بالا تنه ماهر توسط موش (T) و بهبود يادگيرى فضايى و غير فضايى در اثر تزريق درون بافتى (شكنج دندانهدار هييو كامي و قشر

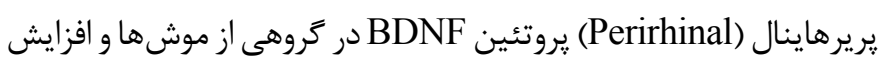
آن در اثر يك هفته دويدن روى تردميل، در گروهى ديخر نشان داده شده

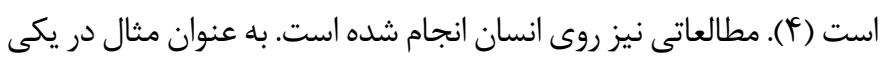
از اين تحقيقات، افزايش غلظت BDNF در سرم انسان (در اثر ورزش)، با بهبود عملكرد تكليف انطباق نام :ههره (matching task Face-name) و تكليف رنت وازه استروب همراه شد (ه). همجنين در مطالعه Egan و همكاران (ץ+ • (ץ)، سطوح BDNF كاهش يافته در مغز انسان با كمبود عملكرد شناختى، عملكرد حافظه مختل شده و افسردگى همراه بود (1). شواهد تحقيقى حاكى از آن است كه يك جندريختى تك نوكلئوتيدى موجود در يكى از نواحى (A single nucleotide polymorphism) زن BDNF (كدين צ \$) برخى از افراد، كه بر روى كروموزوم ال قرار

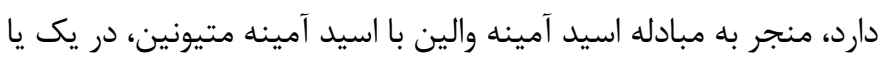
هر دو آلل موجود در اين ناحيه ميىشود. اين رخداد منجر به تمايز سه نوع زنوتايي مىشود؛ يعنى افراد با دو والين، افراد با يك والين و يك متيونين و افراد با دو متيونين. به افراد حامل دو والين و يا دو متيونيين، هموزيگوت مى گويند، و به افراد حامل يك والين و يك متيونين (Homozygote) هتروزيگوت مى گويند (1). در جوامع مختلف نسبت خاصى از حاملان اين نوع زنوتايڤها وجود دارد. به عنوان مثال در آلمان اين نسبت •ع درصد براى val/val و است و • أ درصد براى

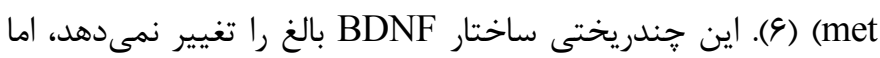
مقدار و شدت بيان آن را دجار اختلال مى كند. جندريختى Val66met همجنين با كاهش رهايى BDNF وابسته به فعاليت همراه است (1). در مطالعات قبلى اين نقصها با تفاوتهاى رفتارى و نوروآناتوميكى در بين افراد جوان مورد مطالعه همراه شده است. براى مثال حجم هييو كامٍ (V)،

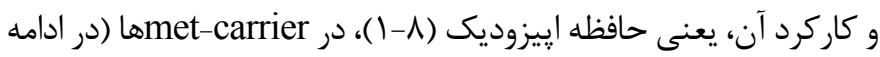
تحقيق به جاى استفاده از اين وازه از عبارت ا|فراد داراى جندريختى يا حاملان متيونين" استفاده مىشود) كاهش مىيابد. با توجه به بيان BDNF در جُندين ساختار مغزى از جمله قشر مغز، اين مين مين فرضيه كه جندريختى ممكن است سيستمهاى ياد كلى عملكردهاى شناختى مختلف را تحتتاثير قرار دهد، وسوسه انخيز است. براى مثال Joundi و همكاران (Y • (Y)، در مطالعهاى نشان دادند كه حاملان متيونين نسبت به \افراد فاقد جندريختى يا حاملان والين" در ياد كيرى تكليف تطابق ديدارى حركتى (adaptation task Visuomotor)، به صورت معنادارى ضعيفتر عمل مى كنند (9). در مطالعهاى ديخر، با استفاده از fMRI و تحريكات مغزى غيرهجومى، ييشنهاد شده است كه 


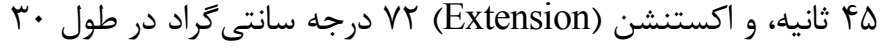
ثانيه، براى •r سيكل ادامه يافت، و با يك اكستنشن نهايى در دماى

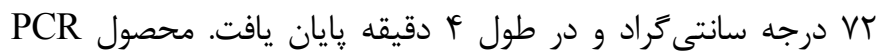

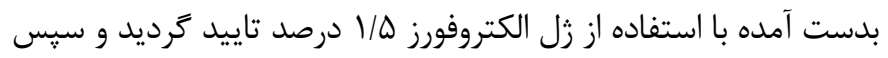

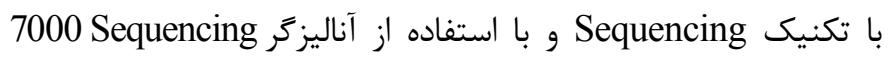

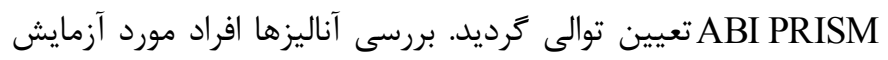

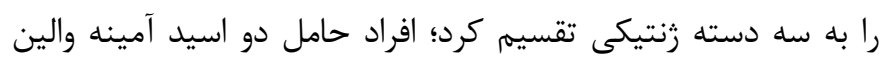

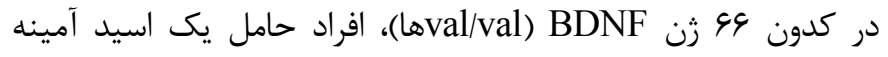

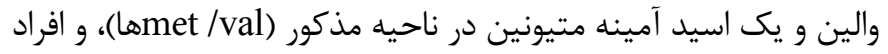

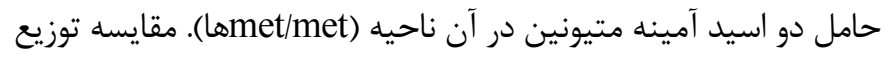

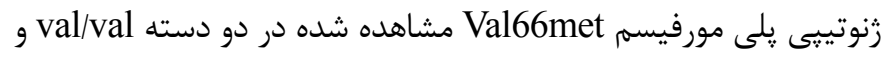

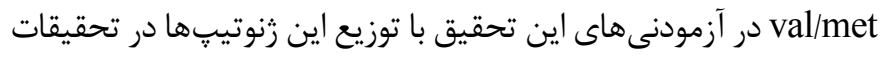

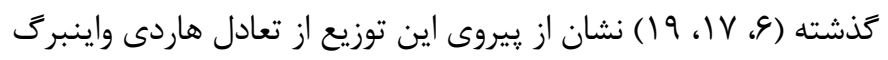
(Hardy-Weinberg equilibrium) آزمون حافظه وكسلر: اين آزمون به عنوان يكى مقياس عينى براى داى دارد

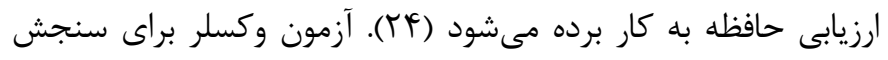
ابعاد مختلف حافظه در طيف سنى خردسال تا بزركسال كاربرد دارد. ضريب اعتبار اين آزمون بالاتر از 1 درصد كزارش شده است (YV). نتيجه • ا سال تحقيق و بررسى در زمينه حافظه علمى، ساده و فورى بوده و اطلاعاتى را براى تفكيك اختلالات عضوى و كنشى حافظه بدست مى دهد.

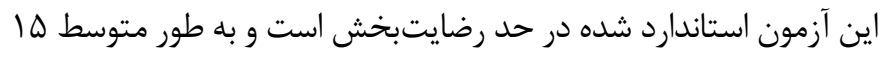
دقيقه به طول مىانجامد و به تفاوت حافظه در سنين مختلف نيز توجه

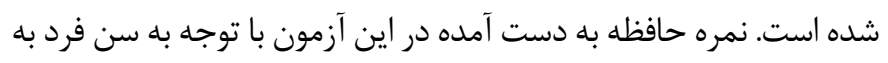

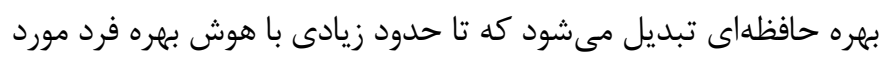

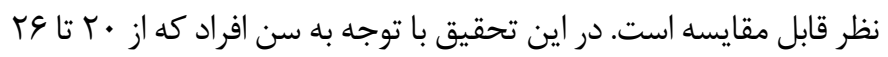

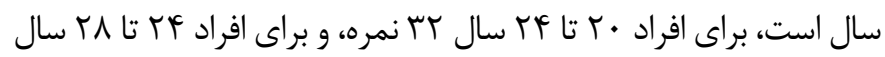
FF ب نمره، به نمره حافظه اضافه شده است تا بهره حافظه به دست آيد (TF).

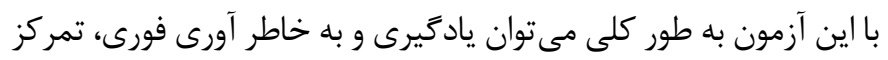

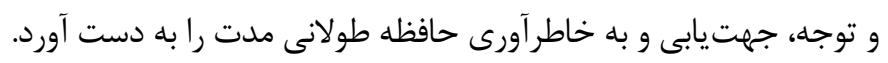

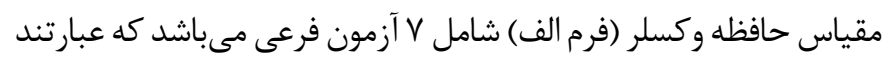

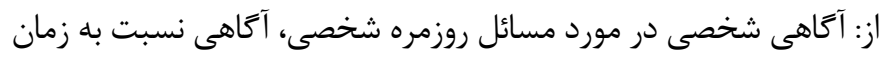

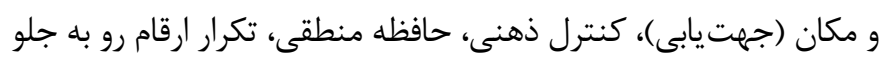

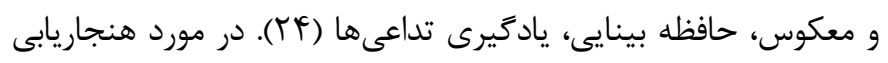

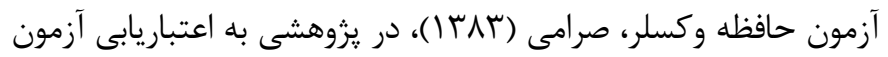

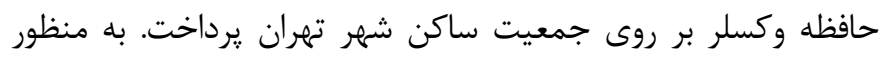

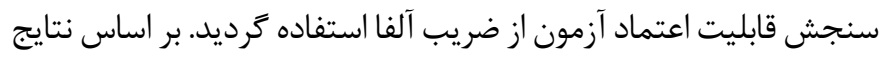

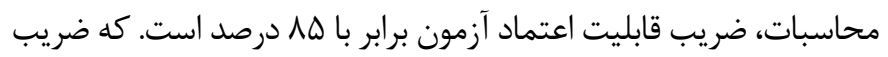

بهره حافظه (Memory Quotient (MQ) كه از طريق آزمون حافظه وكسلر اندازهيرى مىشود تا حدود زيادى با هوشبهر فرد در ارتباط است

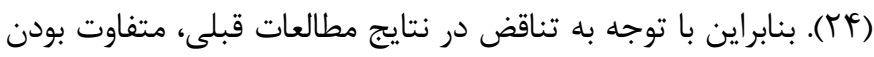

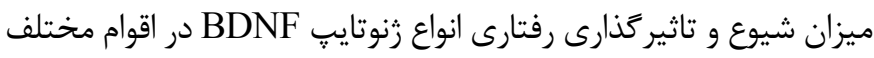

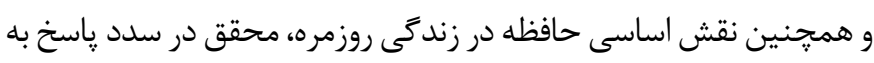

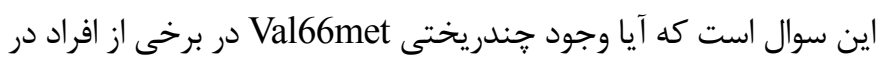

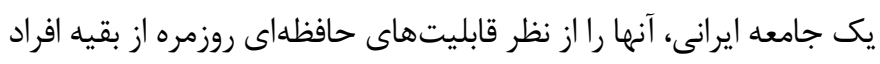

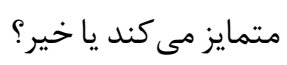

\section{روش كار}

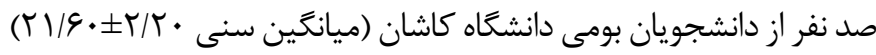
در اين مطالعه شركت داشتند. فرآيند تحقيق براى افراد توضيح داده شد اندان

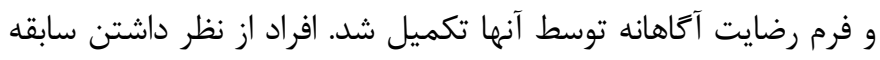

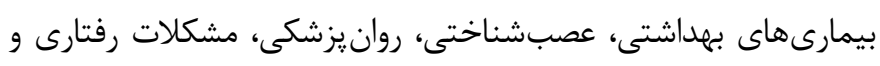

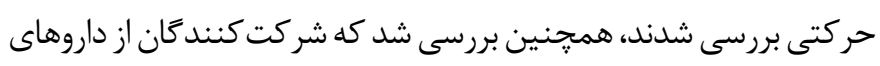

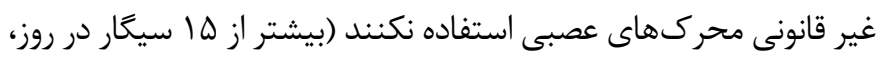

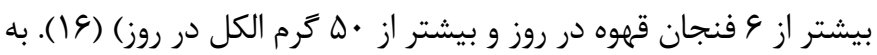
دليل اثر احتمالى فعاليت هورمونهاى جنسى بر تنظيم بيان BDNF

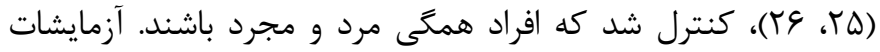

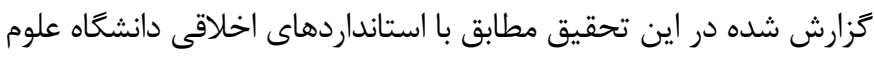
يزشكى كاشان انجام شد.

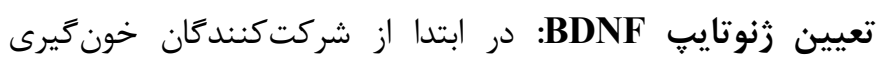

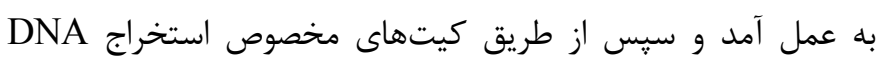

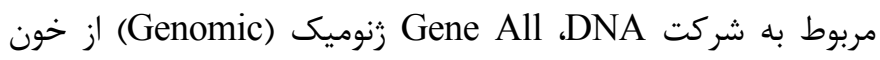
كامل و به وسيله روش ستونى تهيه گرديد. براى تعيين خندريختى

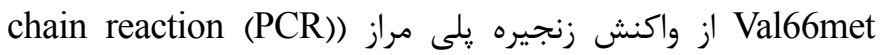
Polymerase استفاده شد. براى انجام PCR، زن BDNF، از برايمرام رو به جلو 5-ACTCTGGAGAGCGTGAAT-3 و يرايمر معكوس ترس 5-ATACTGTCACACACGCTG-3 استفاده گَرديد. مقادير مواد

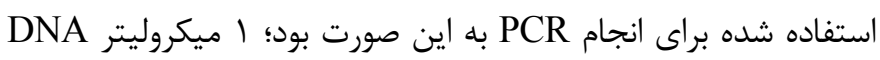

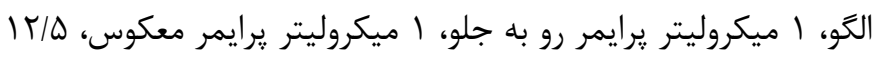

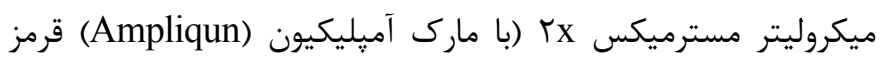

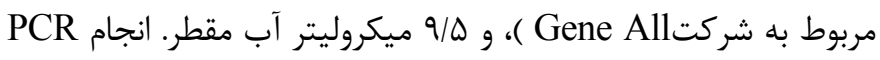
با استفاده از دستگاه ترموسايكلر Lab Net (Thermal cycler) آمريكا، با دناتوراسيون (Denaturation) اوليه در دماى له9 درجه سانتى براى ז/ دقيقه آغاز شد، و با دناتوراسيون له درجه سانتى گراد در

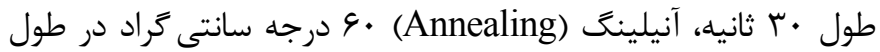


شاخص هاى توصيفى شركت كنندكان از قبيل تعداد، سن، جنسيت، نمرات حافظه و بهره حافظه نشان داده شده است. در ادامه به منظور آزمون فرضيه تحقيق از آزمون تحليل واريانس جند متغيره (MANOVA) استفاده شد كه نتايج آن در جدول ب قابل مشاهده است. همانطور كه در جدول r مشاهده مىشود، نتايج آزمون لامبداى ويلكز نشان مى دهد كه تفاوت معنادارى بين دو گروه در متغيرهاى

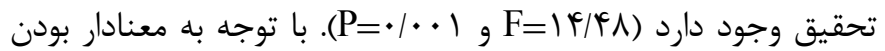
آزمون تحليل واريانس جند متغيره، در ادامه هر يك از متغيرها به صورت جداكانه به وسيله آزمون تحليل واريانس يك طرفه مورد بررسى قرار كرفت كه نتايج آن نشان داد، هم در نمره حافظه (P= F/ F

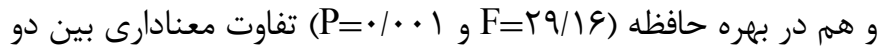
گروه تحقيق وجود دارد، به طورى كه افراد فاقد جندريختى عملكرد بهترى از حاملان متيونين داشتند.
آلفاى به دست آمده بيانگر دقت، درجه ثبات و هماهنكى بالاى آزمون حافظه وكسلر در امر سنجش آزمون (حافظه) بر روى نمونه ايرانى است. با تحليل عوامل آزمون، تمام همبستخى هاى متغيرها با هم معنادار مى باشد

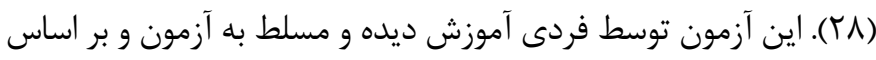
دستورالعمل مربوطه صورت گرفت. به منظور بررسى نرمال بودن توزيع دادهها و همگنى واريانسها از

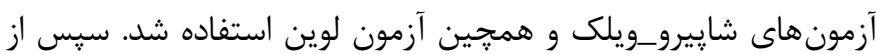
آزمون تحليل واريانس جند متغيره و آزمون لامبداى ويلكز به منظور بررسى لـ تفاوت بين متغيرهاى تحقيق (نمره و بهره حافظه) استفاده شد. در همه تحليل هاى آمارى ه • P P به عنوان شاخص معنادارى در نظر كرفته شد.

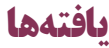

در قسمت آمار توصيفى ابتدا ويزگكىهاى جمعيتشناختى مورد بررسى

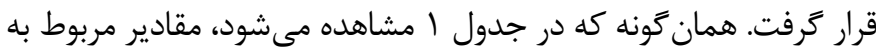

جدول (. شاخص هاى توصيفى شركت كنندكان (ميانخين و انحراف معيار)

\begin{tabular}{|c|c|c|}
\hline $\begin{array}{c}\text { گروه حاملان متيونين } \\
\text { (met/met + val/met) }\end{array}$ & كروه حاملان والين & متغيير \\
\hline $\mid q+r$. & f\& & تعداد \\
\hline$r|(\Delta) \pm r / 9|$ & TI/VTET/Tr & 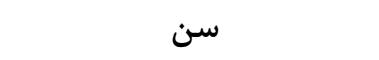 \\
\hline$\Delta / q 1 \pm \cdot / T q$ & $\Delta / ৭ \varphi \pm \cdot / T /$ & خرده مقياس آكاهى شخصى \\
\hline$|\varphi| 94 \pm \cdot|9|$ & $f / \Lambda \cdot \pm \cdot / \mathscr{F} \Delta$ & خرده مقياس جهت يابى \\
\hline $1 / 09 \pm \cdot 199$ & $\Lambda / \vee \wedge \pm \cdot / \Delta \Delta$ & خرده مقياس كنترل ذهنى \\
\hline$|r / V| \pm r / r$. & $19 / V Y \pm T / V F$ & خرده مقياس حافظه منطقى \\
\hline$\Delta / \mathcal{F} I \pm \cdot / V \Delta$ & $\Delta / \Lambda \varepsilon \pm \cdot / V F$ & خرده مقياس تكرار ارقام \\
\hline $1 \cdot|9 V \pm 1 / 4|$ & $\mid 1 / 91 \pm 1 / 4 T$ & خرده مقياس حافظه بينايى \\
\hline$|r / \Lambda € \pm r /| \varphi$ & $19 / 94 \pm Y / 1 V$ & خرده مقياس يادگيرى تداعى \\
\hline$G T / \Lambda I \pm V / F T$ & $\vee \cdot / \pi \wedge \pm \varepsilon / \Delta q$ & نمره كل حافظه \\
\hline$৭ \Delta / \cdot \cdots \pm \vee / \Upsilon \wedge$ & 1. $r / \Delta \Delta \pm \varepsilon / 4 \varepsilon$ & بهره حافظه (MQ) \\
\hline
\end{tabular}

جدول r. تحليل واريانس جندمتغيره (MANOVA) جهت بررسى تفاوت متغيرهاى نمره كل حافظه و بهره حافظه

\begin{tabular}{|c|c|c|c|c|c|c|}
\hline توان آمارى & $\mathbf{P}$ & $\mathbf{F}$ & Df درجه آزادى & Df فرضيه Df & مقدار & منبع تغيير \\
\hline . & $\cdot|\cdot \cdot|^{*}$ & $\mid F / F A$ & qV & r & $\cdot / V V$ & آزمون لامبداى ويلكز \\
\hline
\end{tabular}




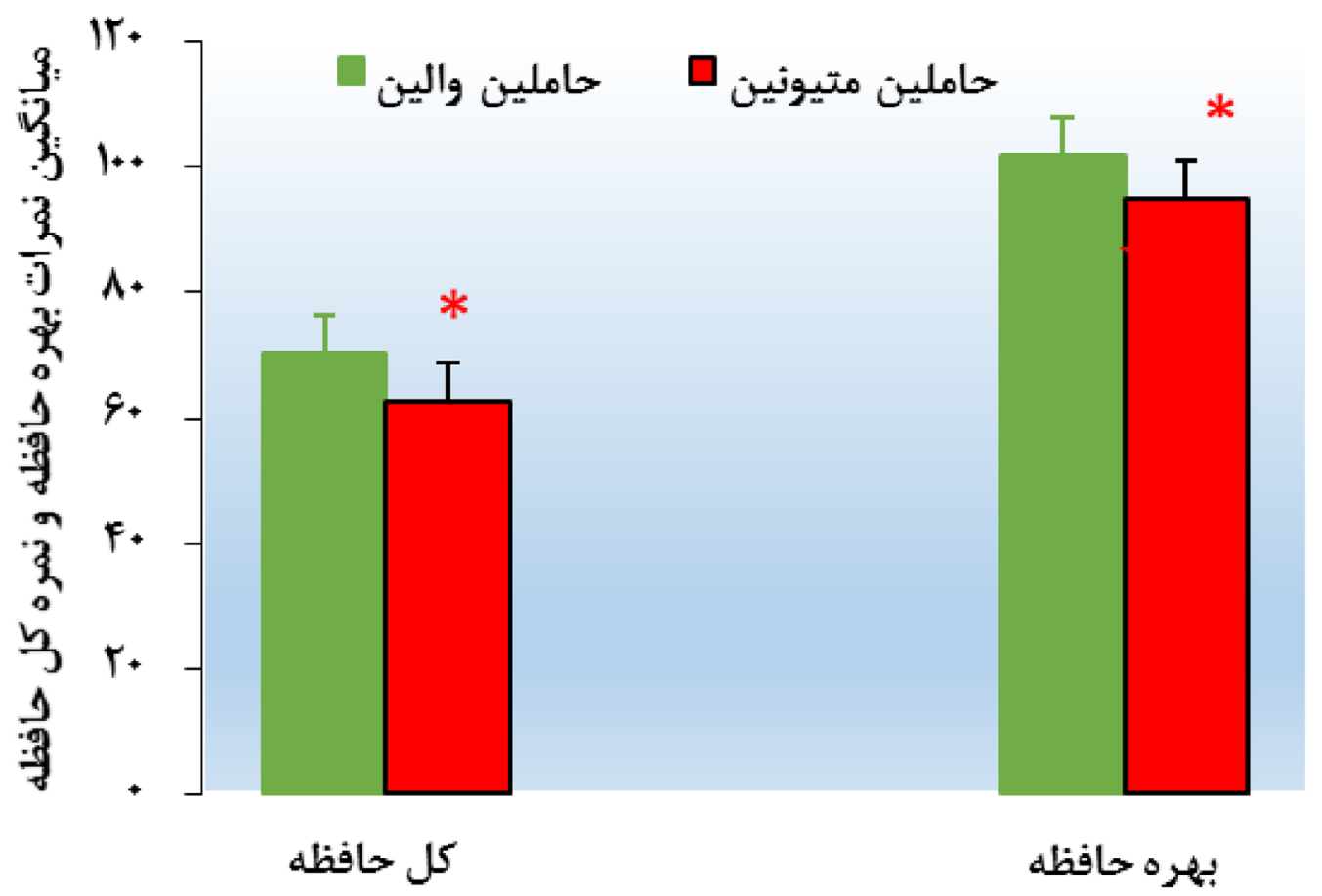

نمودار 1. ميانگين نمرات بهره حافظه و نمره كل حافظه در گروههاى تحقيق

شده است هر عاملى كه موجب افزايش سطح BDNF در انسان شود، مىتواند به تغييراتى در برخى عملكردهاى شناختى از جمله، يادگيرى

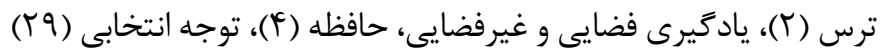

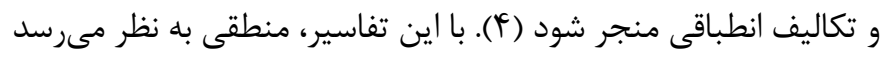

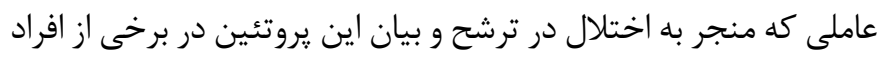

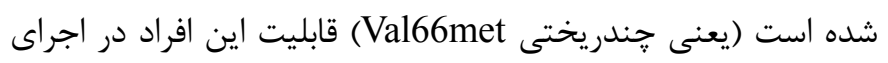

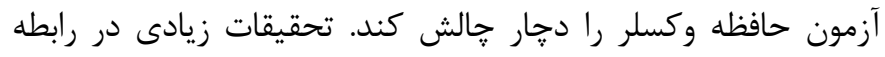

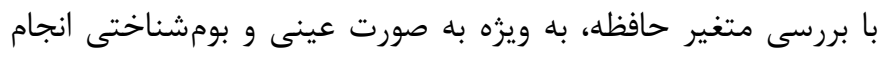

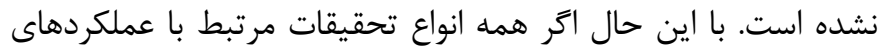
شناختى را در نظر بخيريم نتايج تحقيق حاضر با نتايج اغلب تحقيقات

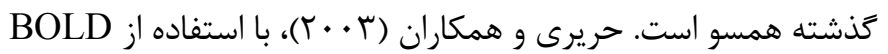

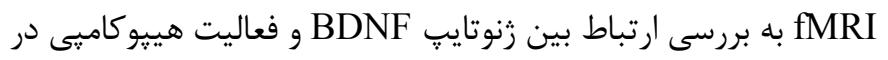

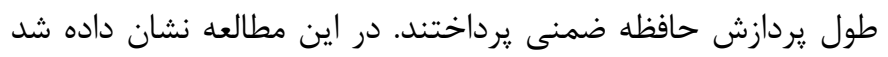

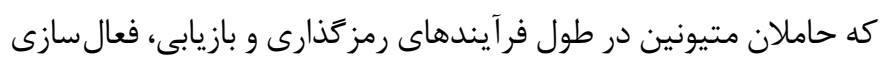

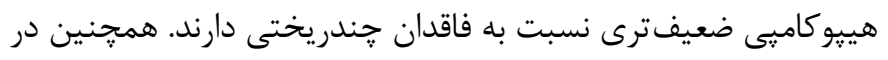
اين تحقيق، حاملان متيونين در تكليف حافظه اخبارى، ضعيفتر از افراد

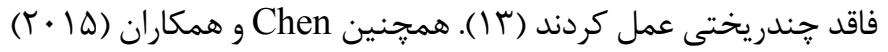
نشان دادند كه حاملان متيونين در هنكام انجام تكاليف حافظه كارى
با استفاده از آزمون حافظه وكسلر، تفاوت افراد فاقد خندريختى

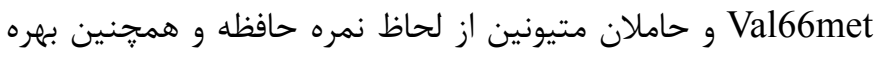

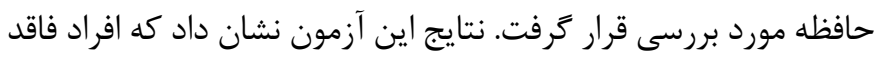

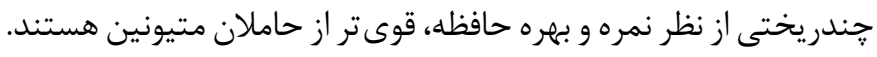

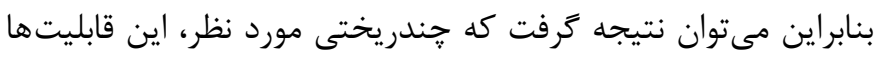

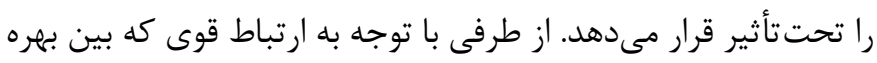

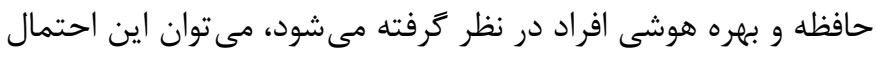
را بالا دانست كه افراد فاقد جندريختى، از هوش بهر بالاترى نيز نسبت به حاملان متيونين برخوردار باشند. همانطور كه در جدول ا مشهود

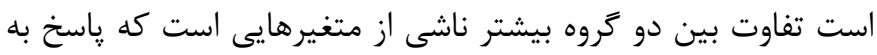

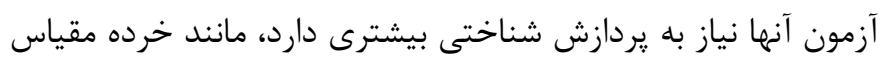

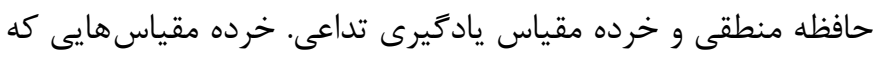

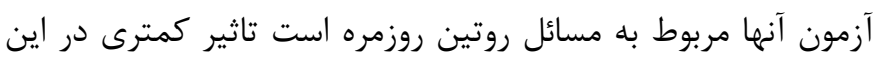

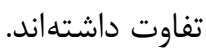
نقش مهمى در حفاظت نورونى و نورونزايى دارد. يزوهش هاى

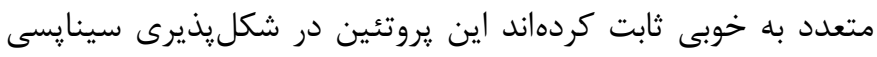

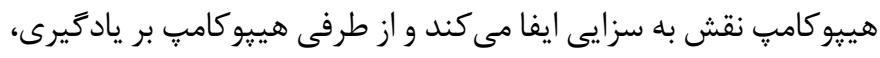

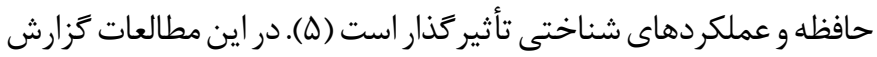


شركت كنند ياد شده باشد. نشان داده شده استروزن كه يك هورمون جنسى زنانه است، محرك بيان BDNF مىباشد (Td)، بنابراين ممكن است به به بهرن اين واسطه نتيجه گيرى در مورد اختلال ايجاد شده توسط جندريختى Val66met

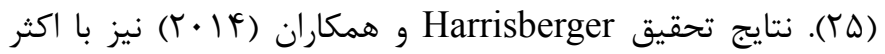
نتايج قبلى و از جمله نتايج تحقيق حاضر همسو نيست. آنها در

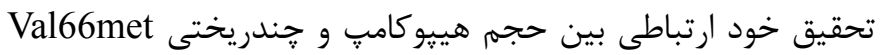
نيافتند. آنها اين تفاوت با تحقيقات ديخر را به تفاوت در حجم نمونهها و روشهاى تحقيقاتى در جمعآورى دادهها نسبت دادند (Yr). در كار اين محققان هر קند متغير جنسيت كنترل نشده است، نمونه تحقيقاتى بسيار بزركترى نسبت به تحقيقات مشابه در نظر كرفته شده

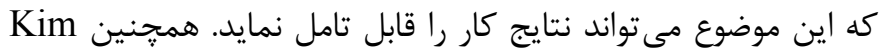
و همكاران در تحقيق خود در سال ها •r با شرايطى مشابه با كار Harrisberger

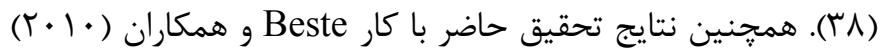
نيز متناقض است (19). در اين تحقيق نتيجهاى متناقض با بيشتر مطالعات در اين حوزه به دست آمد. آنها نشان دادند حاملان متيونين نسبت به افراد فاقد جندريختى توانايى بازدارى پاسخ بهترى دارند. در اين مطالعه دليل اين امر در سطوح سيستمى جستجو شده است. توانايى بازدارى ياسخ به وسيله جرخههاى عقدههاى قاعدهاى كنترل nigro- منجر به كاهش در فعاليت BDNF مئردو و اختلال در بيان striatal در عقدهاى قاعدهاى مىشود. اين كاهش اترجّه منجر به دانه

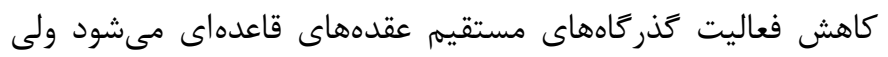
فعاليت كذر كاههاى غيرمستقيم آن را افزايش مىدهد. اين امر منجر به تغيير كذر كاه غالب در حاملان متيونين مىشود (9 (1). علاوه بر

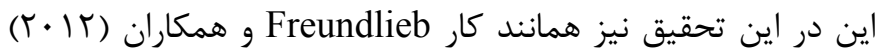

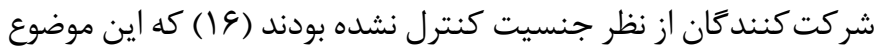
نيز مىتواند تفاوت در نتايج اين تحقيق با تحقيق حاضر را رقم بزند. در تحقيق حاضر سعى شد از ابزارهاى كاغذى و آزمايشكاهى معتبر و استاندارد براى استخراج نتايج معتبر استفاده شود و تا حد امكان

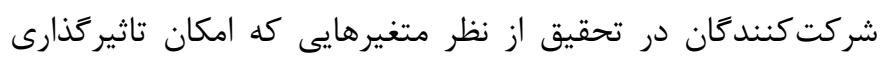

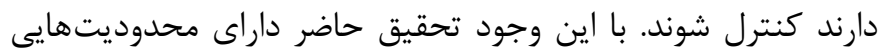
نيز بود كه از آن جمله مى توان به عدم توانايى كنترل تفاوت در حالات روانى، تفاوت در ميزان و نوع فعاليتهاى ورزشى روزمره و همجنين تفاوت در ميزان و كيفيت خواب افراد شركت كننده در جند روز قبل از

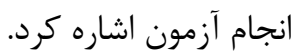

فعالسازى هييو كاميى قابلتوجهى نشان ندادند و به صورت معنادارى در اين تكاليف ضعيفتر از افراد فاقد جندريختى بودند (• (ّ). علاوه بر اين، طى بررسى اثر فعاليت بدنى بر BDNF سالمندان، نتايج نشان

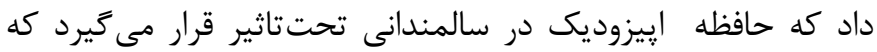
فاقد جندريختى مورد نظر هستند و سالمندان حامل متيونين از فعاليت

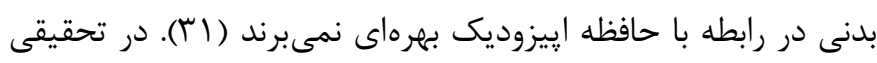

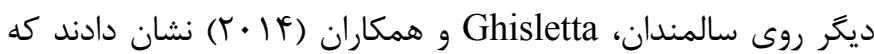
جندريختى Val66met سرعت ادراك در سالمندان را كاهش مى دهد

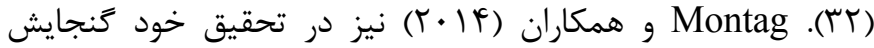
حافظه بلندمدت ضعيفترى را در حاملان متيونين نسبت به افراد فاقد جندريختى يافتند (سب). همجنين Jasinska و همكاران نيز در تحقيق

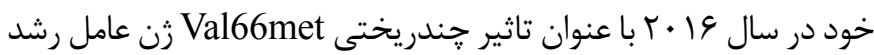

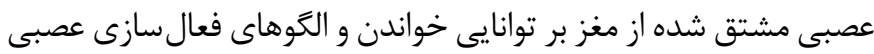

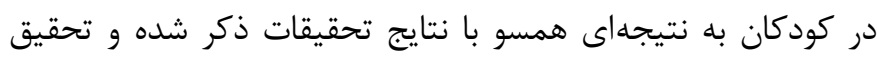

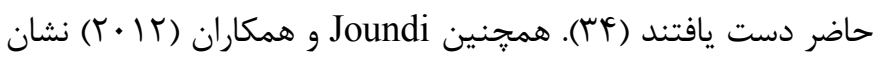
دادند حاملان متيونين در انجام تكليف تطابق ديدارى حركتى به صورت

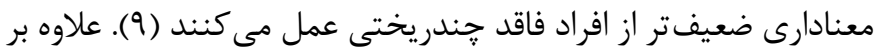

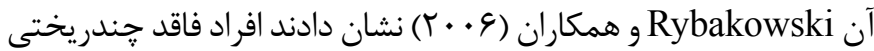
تكليف مرتب كردن كارت ويسكانسين را كه تكليفى است مربوط به عملكردهاى اجرايى لوب ييشانى، به شكل ضعيفترى نسبت به حاملان متيونين انجام مىدهند. اين محققان نتايج حاصل از تحقيق خود را به نقش احتمالى BDNF در ساختارهاى قشرى يِيش ييشانى نسبت دادند

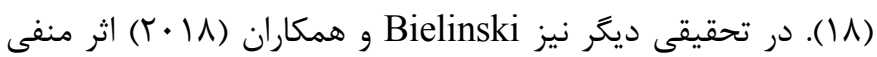

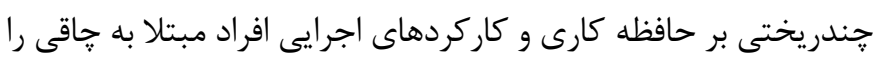

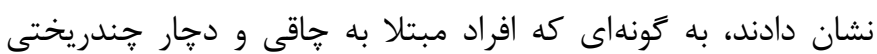
Val66met عملكرد ضعيفترى نسبت به افراد مبتلا به جاقى و فاقد اين جندريختى داشتند (ضץ). همجنين Marqués-Iturria و همكاران

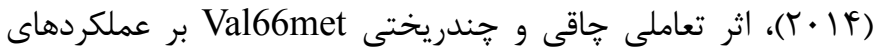
اجرايى ساختارهاى مغزى فرونتال را بررسى كردند و به اين نتيجه رسيدند كه افراد فاقد جندريختى مى توانند از اين نظر بر افراد حان حامل متيونين برترى داشته باشند (ع). با اين حال نتايج تحقيق حاضر با نتيجه تحقيق Freundlieb و

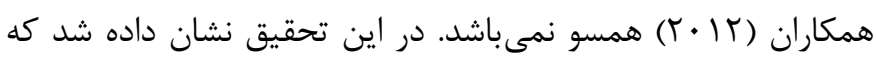
تفاوتى بين دو گروه در تكليف زمان عكسالعمل سريالى و تكليف يادگيرى وازَّان ارتباطى، كه هردو الكوهاى يادگيرى ينهان كوتاه مدت هستند، وجود ندارد (\&). تناقض نتيجه تحقيق حاضر با تحقيق

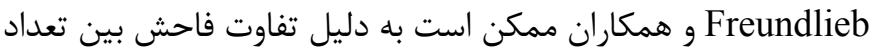


سخن كفته شود و براى حصول اطمينان تحقيقات بيشترى در آينده انجام شود.

\section{تشكر و قدرهانى}

شايسته است كه از افراد شركت كننده در اين تحقيق كه مورد آزمايشات مربوطه قرار كرفتند كمال تشكر را داشته باشه. شايان ذكر است كه آنه

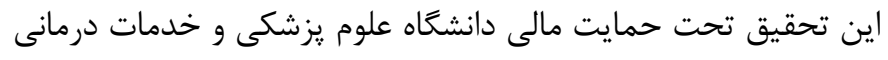

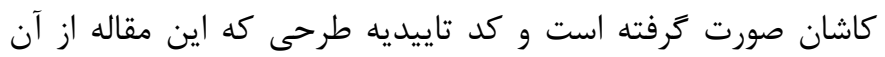

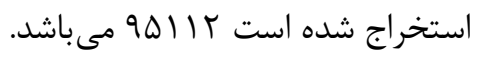

\section{References}

1. Egan MF, Kojima M, Callicott JH, Goldberg TE, Kolachana BS, Bertolino A, et al. The BDNF val66met polymorphism affects activity-dependent secretion of BDNF and human memory and hippocampal function. Cell. 2003;112(2):257-269.

2. Ou L-C, Gean P-W. Regulation of amygdala-dependent learning by brain-derived neurotrophic factor is mediated by extracellular signal-regulated kinase and phosphatidylinositol-3-kinase. Neuropsychopharmacology. 2006;31(2):287-296. 3. Von dem Bussche M. The role of brain-derived neurotrophic factor in cortical motor learning [PhD Thesis]. San Diego:University of California;2007.

4. Griffin EW, Bechara RG, Birch AM, Kelly AM. Exercise enhances hippocampal-dependent learning in the rat: Evidence for a BDNF-related mechanism. Hippocampus. 2009;19(10):973-980.

5. Griffin EW, Mullally S, Foley C, Warmington SA, O’Mara SM, Kelly AM. Aerobic exercise improves hippocampal function and increases BDNF in the serum of young adult males. Physiology \& Behavior. 2011;104(5):934-941.

6. Gajewski PD, Hengstler JG, Golka K, Falkenstein M, Beste

C. The Met-allele of the BDNF Val66Met polymorphism enhances task switching in elderly. Neurobiology of Aging. 2011;32(12):2327.e7-2327.e19.

7. Pezawas L, Verchinski BA, Mattay VS, Callicott JH, Kolacha- na BS, Straub RE, et al. The brain-derived neurotrophic factor val66met polymorphism and variation in human cortical morphology. Journal of Neuroscience. 2004;24(45):10099-10102.

8. Ho B-C, Milev P, O’Leary DS, Librant A, Andreasen NC, Wassink TH. Cognitive and magnetic resonance imaging brain morphometric correlates of brain-derived neurotrophic factor Val66Met gene polymorphism in patients with schizophrenia and healthy volunteers. Archives of General Psychiatry. 2006;63(7):731-740.

9. Joundi RA, Lopez-Alonso V, Lago A, Brittain J-S, Fernandez-del-Olmo M, Gomez-Garre P, et al. The effect of BDNF val66met polymorphism on visuomotor adaptation. Experimental Brain Research. 2012;223(1):43-50.

10. McHughen SA, Rodriguez PF, Kleim JA, Kleim ED, Crespo LM, Procaccio V, et al. BDNF val66met polymorphism influences motor system function in the human brain. Cerebral Cortex. 2009;20(5):1254-1262.

11. McHughen SA, Pearson-Fuhrhop K, Ngo VK, Cramer SC. Intense training overcomes effects of the Val66Met BDNF polymorphism on short-term plasticity. Experimental Brain Research. 2011;213(4):415-422.

12. Antal A, Chaieb L, Moliadze V, Monte-Silva K, Poreisz $\mathrm{C}$, Thirugnanasambandam N, et al. Brain-derived neurotrophic 
factor (BDNF) gene polymorphisms shape cortical plasticity in humans. Brain Stimulation. 2010;3(4):230-237.

\section{Hariri AR, Goldberg TE, Mattay VS, Kolachana BS, Call-} icott JH, Egan MF, et al. Brain-derived neurotrophic factor val66met polymorphism affects human memory-related hippocampal activity and predicts memory performance. Journal of Neuroscience. 2003;23(17):6690-6694.

14. Eker C, Kitis O, Ozan E, Okur H, Eker OD, Ersoy MA, et al. BDNF Gene Val66met Polymorphism Associated Grey Matter Changes in Human Brain. Klinik Psikofarmakoloji Bulteni. 2005;15(3):104-111.

15. Voti PL, Conte A, Suppa A, Iezzi E, Bologna M, Aniello $\mathrm{M}$, et al. Correlation between cortical plasticity, motor learning and BDNF genotype in healthy subjects. Experimental Brain Research. 2011;212(1):91-99.

16. Freundlieb N, Philipp S, Schneider SA, Brüggemann N, Klein C, Gerloff C, et al. No association of the BDNF val66met polymorphism with implicit associative vocabulary and motor learning. PloS One. 2012;7(11):e48327.

17. Tonacci A, Borghini A, Mercuri A, Pioggia G, Andreassi MG. Brain-derived neurotrophic factor (Val66Met) polymorphism and olfactory ability in young adults. Journal of Biomedical Science. 2013;20(1):57.

18. Rybakowski J, Borkowska A, Skibinska M, Hauser J. Illness-specific association of val66met BDNF polymorphism with performance on wisconsin card sorting test in bipolar mood disorder. Molecular Psychiatry. 2006;11(2):122-124.

19. Beste C, Baune B, Domschke K, Falkenstein M, Konrad C. Paradoxical association of the brain-derived-neurotrophic-factor val66met genotype with response inhibition. Neuroscience. 2010;166(1):178-184.

20. Shimizu E, Hashimoto K, Iyo M. Ethnic difference of the BDNF 196G/A (val66met) polymorphism frequencies: The possibility to explain ethnic mental traits. American Journal of Medical Genetics Part B: Neuropsychiatric Genetics. 2004;126(1):122-123.

21. Bath KG, Lee FS. Variant BDNF (Val66Met) impact on brain structure and function. Cognitive, Affective, \& Behavioral Neuroscience. 2006;6(1):79-85.

22. Pivac N, Kim B, Nedic G, Ho Joo Y, Kozaric-Kovacic D, Pyo Hong J, et al. Ethnic differences in brainderived neurotrophic factor Val66Met polymorphism in Croatian and Korean healthy participants. Croatian Medical Journal. 2009;50(1):49-54.

23. Leclercq M, Zimmermann P. Applied neuropsychology of attention: theory, diagnosis and rehabilitation. New York:Psychology Press;2004.

24. Wechsler, D. Wechsler Memory Scale-Revised manual. New York:Psychological Press;1987.

25. Zhou J, Zhang H, Cohen RS, Pandey SC. Effects of estrogen treatment on expression of brain-derived neurotrophic factor and cAMP response element-binding protein expression and phosphorylation in rat amygdaloid and hippocampal structures. Neuroendocrinology. 2005;81(5):294-310.

26. Carbone DL, Handa RJ. Sex and stress hormone influences on the expression and activity of brain-derived neurotrophic factor. Neuroscience. 2013;239:295-303.

27. Khodapanahi MK. Physiological psychology. Tehran:Samt publication;2008. (Persian)

28. Sarrami GH. Standardization of wechsler memory scale in Tehran population. Journal of Psychology and Education. 1994;9(3):18-29. (Persian)

29. Shayan A, Bagherzadeh F, Shahbazi M, Choobineh S. The effect of two types of exercise (endurance and resistance) on attention and brain derived neurotropic factor levels in sedentary students. Motor Development and Learning. 2015;6(4):433-452. 30. Chen CC, Chen CJ, Wu D, Chi NF, Chen PC, Liao YP, et al. BDNF Val66Met polymorphism on functional MRI during n-back working memory tasks. Medicine. 2015;94(42):e1586. 31. Canivet A, Albinet CT, Andre N, Pylouster J, Rodriguez-Ballesteros M, Kitzis A, et al. Effects of BDNF polymorphism and physical activity on episodic memory in the elderly: a cross sectional study. European Review of Aging and Physical Activity. 2015;12(1):1-9.

32. Ghisletta P, Backman L, Bertram L, Brandmaier AM, 
Gerstorf D, Liu T, et al. The Val/Met polymorphism of the brain-derived neurotrophic factor (BDNF) gene predicts decline in perceptual speed in older adults. Psychology and $\mathrm{Ag}$ ing. 2014;29(2):384-392.

33. Montag C, Felten A, Markett S, Fischer L, Winkel K, Cooper A, et al. The role of the BDNF Val66Met polymorphism in individual differences in long-term memory capacity. Journal of Molecular Neuroscience. 2014;54(4):796-802.

34. Jasinska KK, Molfese PJ, Kornilov SA, Mencl WE, Frost SJ, Lee M, et al. The BDNF Val66Met polymorphism influences reading ability and patterns of neural activation in children. PloS One. 2016;11(8):e0157449.

35. Bielinski M, Lesiewska N, Jaracz M, Tomaszewska M, Sikora M, Mieczkowski A, et al. Brain-derived neurotrophic factor val66met polymorphism in contex of executive functions and working memory in obese patients. Neuropsychiatry.
2018;8(1):111-118.

36. Marques-Iturria I, Garolera M, Pueyo R, Segura B, Hernan I, Garcia-Garcia I, et al. The interaction effect between BDNF val66met polymorphism and obesity on executive functions and frontal structure. American Journal of Medical Genetics Part B: Neuropsychiatric Genetics. 2014;165(3):245-253.

37. Harrisberger F, Spalek K, Smieskova R, Schmidt A, Coynel D, Milnik A, et al. The association of the BDNF Val66Met polymorphism and the hippocampal volumes in healthy humans: A joint meta-analysis of published and new data. Neuroscience \& Biobehavioral Reviews. 2014;42:267-278.

38. Kim A, Fagan AM, Goate AM, Benzinger TL, Morris JC, Head D, et al. Lack of an association of BDNF Val66Met polymorphism and plasma BDNF with hippocampal volume and memory. Cognitive, Affective, \& Behavioral Neuroscience. 2015;15(3):625-643. 